\title{
Multimorbidity, dementia and health care in older people: a population-based cohort study
}

\author{
Marcello Tonelli MD SM, Natasha Wiebe MMath PStat, Sharon Straus MD PhD, \\ Martin Fortin MD MSc, Bruce Guthrie MBBS PhD, Matthew T. James MD PhD, \\ Scott W. Klarenbach MD MSc, Helen Tam-Tham MSc, Richard Lewanczuk MD PhD, \\ Braden J. Manns MD MSc, Hude Quan MD PhD, Paul E. Ronksley PhD, Peter Sargious MD, \\ Brenda Hemmelgarn MD PhD; for the Alberta Kidney Disease Network
}

\section{Abstract}

Background: Little is known about how multimorbidity, dementia and increasing age combine to influence health outcomes or utilization. Our objective was to examine the joint associations between age, dementia and burden of morbidity with mortality and other clinical outcomes.

Methods: We did a retrospective population-based cohort study of all adults aged 65 years and older residing in Alberta, Canada, between 2002 and 2013. We used validated algorithms applied to administrative and laboratory data from the provincial health ministry to assess the presence/absence of dementia and 29 other morbidities, and their associations with mortality (our primary outcome), other clinical outcomes (emergency department visits, all-cause hospital admissions) and a proxy for loss of independent living (discharge to long-term care). Cox and Poisson models were adjusted for year-varying covariates. A 3-way interaction was modelled for dementia, the number of comorbidities, and age.

Results: There were 610457 adults aged 65 years and older living in Alberta over the study period. Over median follow-up of 6.8 years, 153125 (25.1\%) participants died and 5569 (0.9\%) were discharged to long-term care. The prevalence of people with at least 3 morbidities was $33.7 \%$ in 2003 and $50.2 \%$ in 2012 . The prevalence of dementia rose from $6.2 \%$ in fiscal year 2003 to $8.3 \%$ in fiscal year 2012, representing a net increase of approximately 13700 people. The likelihood of all 4 outcomes increased with age and with greater burden of morbidity; the presence of dementia further increased these risks. For example, the risk of mortality increased by 1.54 to 6.38 in the presence of dementia, depending on age and morbidity burden. The risk associated with dementia was attenuated by increasing comorbidity.

Interpretation: Older age, multimorbidity and dementia are all strongly correlated with adverse health outcomes as well as a proxy for loss of independent living. The increasing prevalences of dementia and multimorbidity over time suggest the need for coordinated national strategies aimed at mitigating the health challenges associated with the aging of the population.

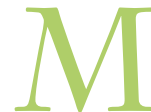
any people have multiple chronic conditions, which is termed multimorbidity. ${ }^{1}$ Multimorbidity is common, and people with 2 or more chronic conditions tend to have worse clinical outcomes and higher health care costs than people in good health and those with a single chronic condition. ${ }^{2-5}$ Multimorbidity increases with age, and among older people it is felt to be a key driver of health care costs and the sustainability of health systems worldwide. ${ }^{6}$ Dementia also poses a major societal burden, and some evidence suggests that dementia is more common in the presence of multimorbidity. ${ }^{7-11}$ However, there are major knowledge gaps concerning the basic epidemiology of multimorbidity among older people; the clinical and economic consequences of multimorbidity; the link between dementia, increasing age and multimorbidity; and the impact of the latter 3 interrelated factors on the capacity to live independently. ${ }^{12}$

We used a population-based data set of people aged 65 years or older and living in Alberta, a Canadian province with 4 million people, to characterize the frequency of dementia and 29 other common chronic conditions. We aimed to examined the joint associations between age, dementia and burden of morbidity with

Competing interests: Dr. James reports receiving an investigatorinitiated research grant from Amgen Canada.

This article has been peer reviewed.

Correspondence to: Marcello Tonelli, cello@ucalgary.ca

CMAJ Open 2017. DOI:10.9778/cmajo.20170052 
mortality and other clinical outcomes (physician visits, emergency department visits and hospital admissions) and especially with loss of capacity for independent living, defined by discharge to a long-term care facility.

\section{Methods}

\section{Data sources and cohort}

Detailed methods are shown in the Appendix 1 (available at www.cmajopen.ca/content/5/3/E623/suppl/DC1). We used the Alberta Kidney Disease Network (AKDN) database, which incorporates data from Alberta Health (AH; the provincial health ministry) such as physician claims, hospital admissions and ambulatory care utilization; the Northern and Southern Alberta Renal Programs; and the clinical laboratories in Alberta. This database has been widely used ${ }^{13-15}$ because of its population-based coverage of a geographically defined area, which includes demographic characteristics, health services utilization and clinical outcomes. Additional information on the database is available elsewhere, including the validation of selected data elements. ${ }^{16}$ All people registered with $\mathrm{AH}$ were included in the database; all Alberta residents are eligible for insurance coverage by $\mathrm{AH}$ and more than $99 \%$ participate in coverage. The database was used to assemble a cohort of adults aged 65 years and older who resided in Alberta, Canada, between May 2002 and March 2013. We followed participants from May 2002, the date of their 65th birthday, or the date they registered with $\mathrm{AH}$ (whichever was later) until March 2013 , their death or their migration out of the province.

\section{Comorbidities}

We classified the presence and absence of 29 comorbidities on the basis of the availability of validated algorithms that could be applied to Canadian claims data and had positive predictive values of at least $70 \% .{ }^{17}$ Dementia was one of the 29 conditions and was defined by the presence of 1 hospital admission or 2 physician claims within 2 years (codes 290, 294.1 and 331.2 from the International Classification of Disease, 9th revision [ICD-9] coding scheme and codes F00-F03, F05.1, G30 and G31.1 from the ICD-10 coding scheme). ${ }^{18}$ We also considered chronic kidney disease as a 30th condition, which was defined by mean annual estimated glomerular filtration rate (eGFR) below $60 \mathrm{~mL} / \mathrm{min}$ per $173 \mathrm{~m}^{2}$ or the presence of albuminuria (albumin:creatinine ratio at least $30 \mathrm{mg} / \mathrm{g}$, protein:creatinine ratio at least $150 \mathrm{mg} / \mathrm{g}$ or dipstick proteinuria $\geq$ trace). Each participant was classified with respect to the presence or absence of dementia and 29 other chronic conditions for each fiscal year. ${ }^{19}$ If a participant developed a condition within a fiscal year or at any point previously (lookback extended as far as April 1994 where records were available), he or she was classified as having the condition. Detailed methods for classifying morbidity status and the specific algorithms used are found elsewhere. ${ }^{17}$

\section{Clinical outcomes}

The primary outcome was time to all-cause death. Key secondary outcomes included the rate of physician visits (primary care physicians or specialists), the rate of emergency department visits and the rate of hospital admissions. We also evaluated loss of capacity for independent living, which was defined by first discharge to a public or private long-term care facility (e.g., nursing homes, auxiliary hospitals) following any hospital admission.

\section{Statistical analyses}

We did analyses with Stata MP 13.1 and reported baseline (first year within follow-up) descriptive statistics as counts and percentages or as medians and interquartile ranges, as appropriate. Secular trend of prevalent dementia was assessed using an autoregressive model of order 1 . Analyses focused on the interactions between the specific exposures of dementia, number of nondementia morbidities, and age.

To examine the associations between dementia, increasing morbidity burden and age with the clinical outcomes, we used a number of models: Cox regression for mortality and longterm care placements; and generalized linear regression using the Poisson distribution with a log link for the rates of physician claims, emergency department visits and hospital admissions (all separately) and a random intercept term for participant. To meet Poisson modelling assumptions, we analyzed the doubling of events (claims, emergency department visits and hospital admissions) rather than absolute increments of 1 event. All covariates were allowed to vary on a year-by-year basis.

\section{Ethics approval}

The study was approved by the universities of Alberta and Calgary.

\section{Results}

\section{Characteristics of study participants}

Participant flow is shown in Appendix 2, supplemental Figure S1 (available at www.cmajopen.ca/content/5/3/E623/suppl/ DC1). There were 610457 participants aged 65 years or older; median follow-up was 6.8 years (range $1 \mathrm{~d}$ to $10.9 \mathrm{yr} ; 2.3 \%$ of participants migrated out of the province before the end of follow-up). The median age of participants was 66 years at baseline (range 65 to $110 \mathrm{yr}$ ), 53.2\% were female, $1.4 \%$ were Aboriginal and $14.8 \%$ resided in a rural location (Table 1 ). The median number of nondementia morbidities was 2 (range 0 to 16); $8.7 \%$ of participants had 5 or more morbidities.

The prevalence of dementia rose over time by approximately $0.2 \%$ per year from $6.2 \%$ in fiscal year 2003 to $8.3 \%$ in fiscal year 2012, representing a net increase of approximately 13700 people. Adjustment for mean age did not attenuate the prevalence of dementia over time. For all age strata, the prevalence of dementia increased in parallel with the number of nondementia morbidities (Figure 1).

\section{Unadjusted likelihood of outcomes}

During follow-up, 153125 (25.1\%) participants died and 5569 $(0.9 \%)$ participants were discharged into long-term care. The rate of physician claims was 1795 per 100 person-years, the 
rate of emergency department visits was 71 per 100 personyears and the rate of hospital admissions was 24 per 100 personyears. Unadjusted rates of mortality and discharge to long- term care increased with increasing age for people with and without dementia. Unadjusted rates of physician visits, emergency department visits and hospital admissions increased with

\begin{tabular}{|c|c|c|c|c|c|c|c|}
\hline \multirow[b]{3}{*}{ Characteristic } & \multirow[b]{3}{*}{ All } & \multicolumn{6}{|c|}{ Group; \% of participants* } \\
\hline & & \multicolumn{2}{|c|}{ Age $65-74$ yr } & \multicolumn{2}{|c|}{ Age 75-84 yr } & \multicolumn{2}{|c|}{ Age $85 \mathrm{yr}+$} \\
\hline & & Dementia & $\begin{array}{c}\text { No } \\
\text { dementia }\end{array}$ & Dementia & $\begin{array}{c}\text { No } \\
\text { dementia }\end{array}$ & Dementia & $\begin{array}{c}\text { No } \\
\text { dementia }\end{array}$ \\
\hline No. & 610457 & 5424 & 435151 & 8652 & 115957 & 9772 & 35501 \\
\hline Male & 46.8 & 50.3 & 49.6 & 39.1 & 42.5 & 27.6 & 33.8 \\
\hline Aboriginal & 1.4 & 3.1 & 1.6 & 0.6 & 0.6 & 0.4 & 0.5 \\
\hline Rural & 14.8 & 13.2 & 15.7 & 10.6 & 13.3 & 10.7 & 11.8 \\
\hline $\begin{array}{l}\text { No. of nondementia } \\
\text { morbidities, median (IQR) }\end{array}$ & $2(1,3)$ & $4(2,5)$ & $1(0,3)$ & $3(2,5)$ & $2(1,3)$ & $3(2,5)$ & $2(1,4)$ \\
\hline None & 23.0 & 5.5 & 25.6 & 6.7 & 17.8 & 6.6 & 19.2 \\
\hline 1 & 26.3 & 12.1 & 28.0 & 13.9 & 24.8 & 13.6 & 19.5 \\
\hline 2 & 21.0 & 15.0 & 21.1 & 15.9 & 21.8 & 18.2 & 19.6 \\
\hline 3 & 13.5 & 16.9 & 12.6 & 17.1 & 15.3 & 19.0 & 15.4 \\
\hline 4 & 7.6 & 14.0 & 6.5 & 14.6 & 9.2 & 14.9 & 10.8 \\
\hline 5 or more & 8.7 & 36.6 & 6.2 & 31.8 & 11.2 & 27.7 & 15.5 \\
\hline Alcohol misuse & 2.3 & 19.1 & 2.2 & 8.5 & 1.5 & 3.1 & 0.9 \\
\hline Asthma & 3.0 & 6.7 & 2.7 & 5.2 & 3.5 & 4.5 & 3.6 \\
\hline Atrial fibrillation & 6.9 & 11.9 & 4.5 & 19.5 & 10.6 & 23.4 & 15.5 \\
\hline Cancer, lymphoma & 0.5 & 0.9 & 0.5 & 0.7 & 0.6 & 0.4 & 0.5 \\
\hline Cancer, metastatic & 1.5 & 2.2 & 1.3 & 2.6 & 2.0 & 2.0 & 2.0 \\
\hline Cancer, nonmetastatic & 5.8 & 6.0 & 5.2 & 8.6 & 7.4 & 7.1 & 6.8 \\
\hline Chronic heart failure & 8.7 & 20.5 & 5.1 & 28.1 & 13.3 & 37.3 & 24.1 \\
\hline Chronic kidney disease & 18.2 & 29.3 & 17.9 & 22.8 & 16.5 & 28.0 & 21.4 \\
\hline Chronic pain & 9.7 & 11.2 & 9.7 & 9.6 & 10.5 & 7.1 & 8.4 \\
\hline Chronic pulmonary disease & 16.3 & 33.6 & 14.1 & 31.3 & 20.1 & 29.0 & 21.2 \\
\hline Chronic viral hepatitis B & 0.1 & 0.2 & 0.1 & $<0.1$ & $<0.1$ & $<0.1$ & $<0.1$ \\
\hline Cirrhosis & 0.2 & 1.3 & 0.2 & 0.4 & 0.1 & 0.1 & $<0.1$ \\
\hline Constipation, severe & 1.5 & 5.7 & 0.9 & 5.7 & 2.0 & 6.2 & 3.5 \\
\hline Depression & 7.3 & 34.5 & 6.5 & 27.2 & 6.9 & 19.5 & 6.8 \\
\hline Diabetes & 16.8 & 29.6 & 16.8 & 23.6 & 16.6 & 17.5 & 13.1 \\
\hline Epilepsy & 1.2 & 10.5 & 1.1 & 3.9 & 0.9 & 2.2 & 0.7 \\
\hline Hypertension & 54.1 & 62.1 & 50.6 & 65.3 & 62.3 & 65.0 & 62.2 \\
\hline Hypothyroidism & 11.3 & 16.3 & 10.5 & 18.0 & 12.4 & 18.8 & 13.5 \\
\hline Inflammatory bowel disease & 0.8 & 1.2 & 0.9 & 0.9 & 0.6 & 0.7 & 0.4 \\
\hline Irritable bowel syndrome & 1.8 & 3.8 & 1.8 & 3.0 & 1.6 & 2.0 & 1.4 \\
\hline Multiple sclerosis & 0.5 & 3.8 & 0.6 & 1.0 & 0.3 & 0.6 & 0.2 \\
\hline Myocardial infarction & 4.3 & 7.9 & 3.8 & 8.0 & 5.1 & 7.2 & 5.8 \\
\hline Parkinson disease & 1.4 & 10.6 & 0.7 & 10.8 & 1.9 & 8.2 & 2.4 \\
\hline Peptic ulcer disease & 0.4 & 1.5 & 0.3 & 1.6 & 0.7 & 1.2 & 0.8 \\
\hline Peripheral vascular disease & 1.8 & 4.5 & 1.5 & 3.9 & 2.4 & 3.0 & 2.4 \\
\hline Psoriasis & 0.7 & 1.6 & 0.7 & 0.9 & 0.6 & 0.7 & 0.5 \\
\hline Rheumatoid arthritis & 3.0 & 5.0 & 2.6 & 4.7 & 3.7 & 4.5 & 3.7 \\
\hline Schizophrenia & 0.9 & 16.2 & 0.7 & 6.0 & 0.4 & 3.4 & 0.3 \\
\hline Stroke or TIA & 9.6 & 30.8 & 6.9 & 33.8 & 12.6 & 33.6 & 17.8 \\
\hline
\end{tabular}




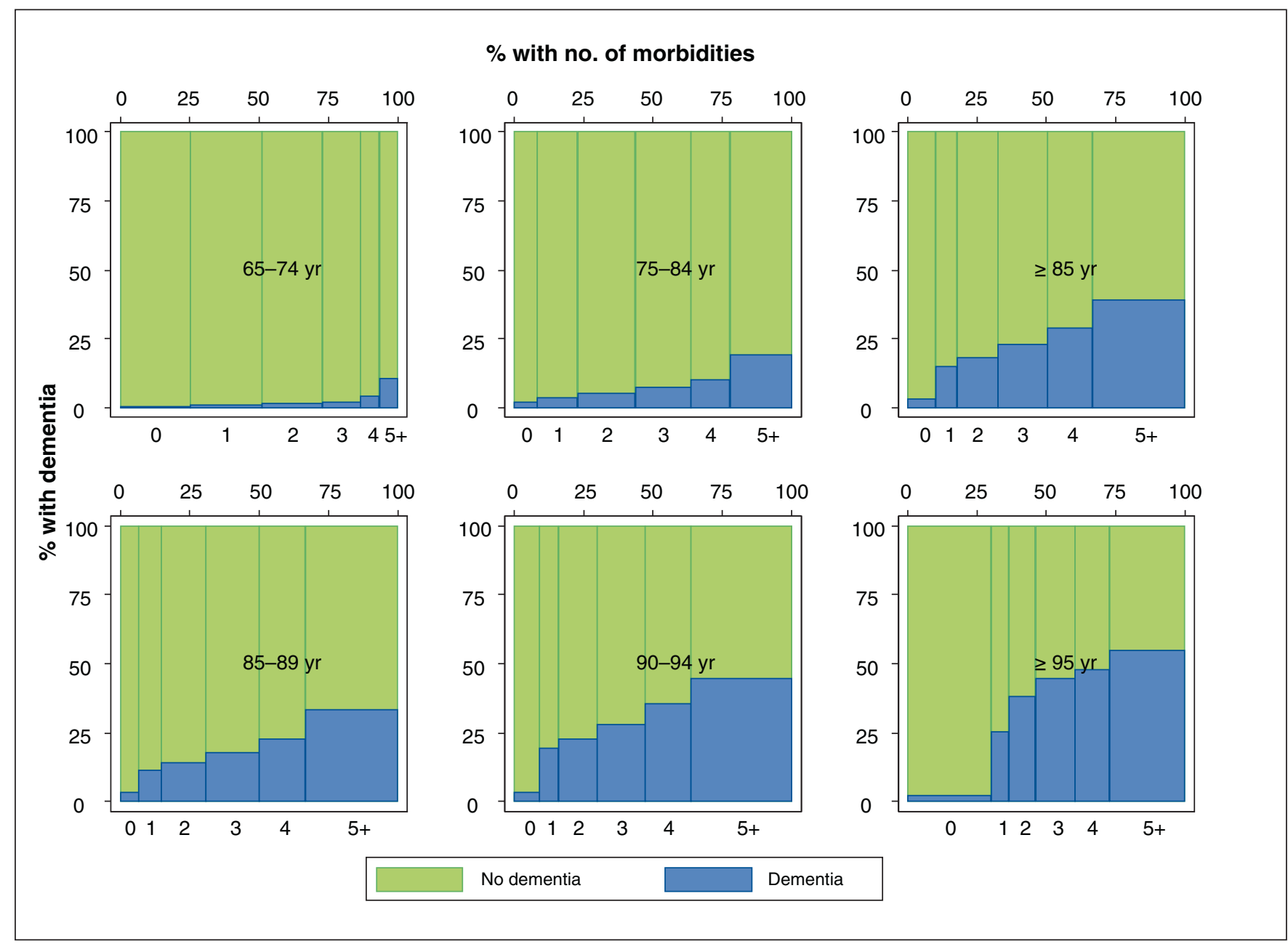

Figure 1: Relative proportion of participants with dementia in fiscal year 2011 by age and number of morbidities. The top row, from left to right, shows participants age 65-74 years, age 75-84 years and age 85 years or older. The bottom row, from left to right, shows participants age 85-89 years, age 90-94 years and age 95 years or older. Within each graph, the bars from left to right show the number of morbidities that participants in that age group have, starting at 0 morbidities and ending at 5 or more. The width of each bar indicates the percentage of participants in each group. The height of each bar indicates the unadjusted percentage of participants with dementia (blue) and the percentage of participants without dementia (green).

age among people without dementia but decreased with age among those with dementia (Appendix 3, Supplemental Table 1 [available at www.cmajopen.ca/content/5/3/E623/suppl/ DC1]).

\section{Adjusted likelihood of outcomes}

The likelihood of all clinical outcomes (death, physician claims, emergency department visits, all-cause hospital admissions, discharge to a long-term care facility) tended to increase with greater burden of morbidity (Figure 2), regardless of the presence of dementia The exceptions were all-cause mortality (for which there was evidence of a J-shaped relation among those with dementia, with the lowest risk of death observed among those with 2 or 3 morbidities) and for discharge to a long-term care facility among people with dementia (the likelihood of which decreased with increasing morbidity) (Figure 2).

The presence of dementia increased the risk of all clinical outcomes, regardless of age and level of morbidity; the excess risk was especially pronounced for mortality and for discharge to a long-term care facility (Figure 2). However, the magnitude of the excess risk for discharge to long-term care that was associated with dementia appeared to decrease with increasing age and morbidity (Table 2; Figure 2). For example, among people with no morbidities, the hazard ratios (HRs) for discharge to longterm care associated with dementia (v. no dementia) were 179.85 (95\% confidence interval [CI] 127.52-253.66), 65.57 (95\% CI 48.64-88.40) and 22.00 (95\% CI 17.15-28.24) among people aged $65-74,75-84$ and at least 85 years, respectively. Among people aged 85 years and older, the HRs associated with dementia for discharge to long-term care for those with 1,2 and 3 morbidities were 3.48 (95\% CI 3.13-3.88), 2.29 (95\% CI 2.14-2.45) and 1.63 (95\% CI 1.56-1.72), respectively. The magnitude of the excess risks for physician visits, emergency department visits or all-cause hospital admissions that were associated with dementia all appeared to decrease with increasing morbidity, but the risks were not consistently modified by age (Table 2; Figure 2). These 


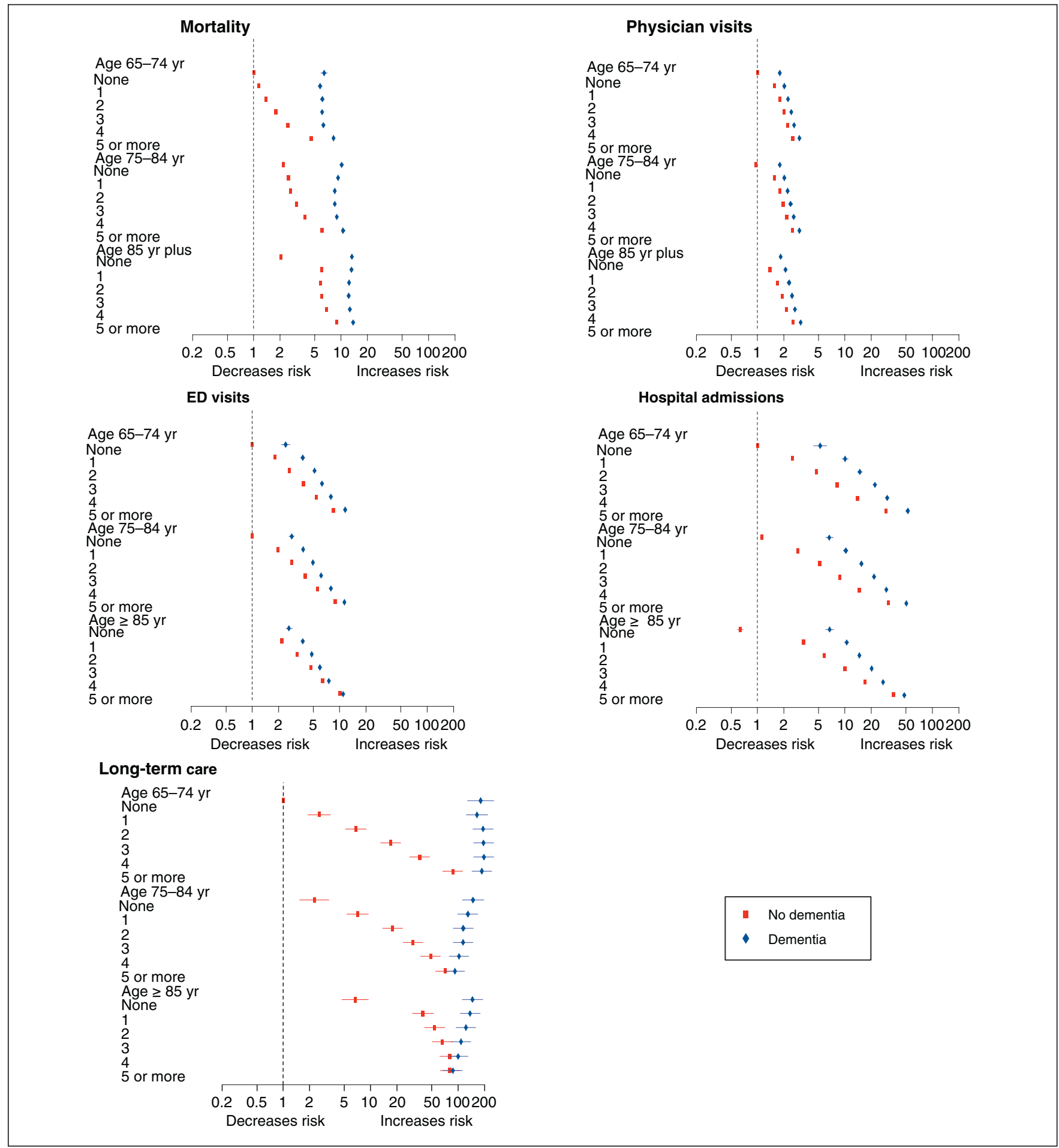

Figure 2: Adjusted risk multiplier for number of morbidities by age and presence of dementia. The risk multipliers are presented by age, number of morbidities and dementia. They are adjusted for the number of morbidities, dementia, age, sex, Aboriginal status and rural/urban residence, and they are relative to people age 65-74 years with no nondementia morbidities. These models include 3-way and 2-way interactions terms for dementia, age and number of morbidities. The first panel shows the hazard ratios for mortality by the number of morbidities. The second, third and fourth panels similarly show the rate ratios for physician visits, ED visits and hospital admissions, respectively. The last panel shows the hazard ratios for discharge to long-term care from hospital. The blue diamond symbols indicate participants with dementia and the red squares indicate those without dementia. The horizontal bars depict $95 \%$ confidence intervals. Along with the risk of mortality and discharge to long-term care, the figure shows the likelihood of a 2-fold increase in the risk of the outcomes with repeat events (i.e., physician visits, ED visits, hospitalizations) that is associated with dementia. For example, a 2-fold increase in the number of physician visits is 1.57 times more likely among those who are aged 65-74 years who have 1 comorbibity and do not have dementia than in those of similar age who have no comorbitiies and do not have dementia. Note: ED = emergency department, LTC = long-term care. 


\section{OPEN}

Research

patterns were also seen when only participants aged 85 years and older were considered (Appendix 4, supplemental Table 2 [available at www.cmajopen.ca/content/5/3/E623/suppl/DC1]).

In contrast to these relative trends in the prognostic importance of dementia, the absolute percentages of partici- pants who died and of those discharged to a long-term care facility (rather than home) increased in parallel with age and number of chronic conditions; the presence of dementia acted as a risk multiplier for both of these adverse outcomes, regardless of age or morbidity burden (Figure 3). For exam-

\begin{tabular}{|c|c|c|c|c|c|c|}
\hline $\begin{array}{l}\text { Age group; } \\
\text { no. of } \\
\text { morbidities }\end{array}$ & $\begin{array}{c}\text { No. of } \\
\text { participant- } \\
\text { years (\%) }\end{array}$ & $\begin{array}{c}\text { Mortality, } \\
\mathrm{HR}(95 \% \mathrm{Cl})\end{array}$ & $\begin{array}{c}\text { Physician } \\
\text { visits, } \\
\text { RR }(95 \% \mathrm{Cl})\end{array}$ & $\begin{array}{c}\text { ED visits, } \\
\text { RR }(95 \% \mathrm{Cl})\end{array}$ & $\begin{array}{c}\text { Hospital } \\
\text { admissions, } \\
\text { RR }(95 \% \mathrm{Cl})\end{array}$ & $\begin{array}{l}\text { Discharge to } \\
\text { long-term care, } \\
\mathrm{HR}(95 \% \mathrm{Cl})\end{array}$ \\
\hline Age 65-74 yr & 2093043 & & & & & \\
\hline None & $\begin{array}{c}409872 \\
(19.6)\end{array}$ & $\begin{array}{c}6.38 \\
(5.86-6.95)\end{array}$ & $\begin{array}{c}1.79 \\
(1.73-1.85)\end{array}$ & $\begin{array}{c}2.40 \\
(2.14-2.70)\end{array}$ & $\begin{array}{c}5.22 \\
(4.38-6.22)\end{array}$ & $\begin{array}{c}179.85 \\
(127.52-253.66)\end{array}$ \\
\hline 1 & $\begin{array}{c}514511 \\
(24.6)\end{array}$ & $\begin{array}{c}5.02 \\
(4.74-5.31)\end{array}$ & $\begin{array}{c}1.29 \\
(1.27-1.32)\end{array}$ & $\begin{array}{c}2.07 \\
(1.94-2.20)\end{array}$ & $\begin{array}{c}4.02 \\
(3.70-4.38)\end{array}$ & $\begin{array}{c}63.74 \\
(53.52-75.91)\end{array}$ \\
\hline 2 & $\begin{array}{c}462717 \\
(22.1)\end{array}$ & $\begin{array}{c}4.43 \\
(4.23-4.63)\end{array}$ & $\begin{array}{c}1.23 \\
(1.21-1.25)\end{array}$ & $\begin{array}{c}1.93 \\
(1.84-2.02)\end{array}$ & $\begin{array}{c}3.14 \\
(2.95-3.33)\end{array}$ & $\begin{array}{c}28.52 \\
(25.34-32.10)\end{array}$ \\
\hline 3 & $\begin{array}{c}320038 \\
(15.3)\end{array}$ & $\begin{array}{c}3.41 \\
(3.27-3.56)\end{array}$ & $\begin{array}{c}1.21 \\
(1.19-1.23)\end{array}$ & $\begin{array}{c}1.65 \\
(1.59-1.71)\end{array}$ & $\begin{array}{c}2.70 \\
(2.57-2.83)\end{array}$ & $\begin{array}{c}11.54 \\
(10.51-12.68)\end{array}$ \\
\hline 4 & $\begin{array}{c}183217 \\
(8.8)\end{array}$ & $\begin{array}{c}2.55 \\
(2.44-2.66)\end{array}$ & $\begin{array}{c}1.20 \\
(1.18-1.22)\end{array}$ & $\begin{array}{c}1.46 \\
(1.41-1.51)\end{array}$ & $\begin{array}{c}2.19 \\
(2.09-2.28)\end{array}$ & $\begin{array}{c}5.41 \\
(4.99-5.88)\end{array}$ \\
\hline 5 or more & $\begin{array}{c}202688 \\
(9.7)\end{array}$ & $\begin{array}{c}1.80 \\
(1.76-1.84)\end{array}$ & $\begin{array}{c}1.20 \\
(1.19-1.21)\end{array}$ & $\begin{array}{c}1.35 \\
(1.33-1.38)\end{array}$ & $\begin{array}{c}1.79 \\
(1.75-1.83)\end{array}$ & $\begin{array}{c}2.16 \\
(2.07-2.26)\end{array}$ \\
\hline Age $75-84$ yr & 1441821 & & & & & \\
\hline None & $\begin{array}{c}146923 \\
(10.2)\end{array}$ & $\begin{array}{c}4.68 \\
(4.46-4.91)\end{array}$ & $\begin{array}{c}1.87 \\
(1.83-1.92)\end{array}$ & $\begin{array}{c}2.80 \\
(2.60-3.01)\end{array}$ & $\begin{array}{c}5.98 \\
(5.36-6.67)\end{array}$ & $\begin{array}{c}65.57 \\
(48.64-88.40)\end{array}$ \\
\hline 1 & $\begin{array}{c}240053 \\
(16.7)\end{array}$ & $\begin{array}{c}3.66 \\
(3.55-3.77)\end{array}$ & $\begin{array}{c}1.31 \\
(1.29-1.32)\end{array}$ & $\begin{array}{c}1.95 \\
(1.88-2.03)\end{array}$ & $\begin{array}{c}3.52 \\
(3.33-3.72)\end{array}$ & $\begin{array}{c}18.20 \\
(15.93-20.79)\end{array}$ \\
\hline 2 & $\begin{array}{c}301412 \\
(20.9)\end{array}$ & $\begin{array}{c}3.19 \\
(3.12-3.27)\end{array}$ & $\begin{array}{c}1.23 \\
(1.22-1.24)\end{array}$ & $\begin{array}{c}1.75 \\
(1.70-1.80)\end{array}$ & $\begin{array}{c}2.99 \\
(2.88-3.10)\end{array}$ & $\begin{array}{c}6.41 \\
(5.94-6.92)\end{array}$ \\
\hline 3 & $\begin{array}{c}271780 \\
(18.9)\end{array}$ & $\begin{array}{c}2.74 \\
(2.68-2.80)\end{array}$ & $\begin{array}{c}1.21 \\
(1.20-1.22)\end{array}$ & $\begin{array}{c}1.54 \\
(1.50-1.57)\end{array}$ & $\begin{array}{c}2.45 \\
(2.38-2.53)\end{array}$ & $\begin{array}{c}3.73 \\
(3.52-3.95)\end{array}$ \\
\hline 4 & $\begin{array}{c}191442 \\
(13.3)\end{array}$ & $\begin{array}{c}2.31 \\
(2.26-2.36)\end{array}$ & $\begin{array}{c}1.20 \\
(1.19-1.21)\end{array}$ & $\begin{array}{c}1.42 \\
(1.39-1.45)\end{array}$ & $\begin{array}{c}2.03 \\
(1.98-2.08)\end{array}$ & $\begin{array}{c}2.12 \\
(2.02-2.23)\end{array}$ \\
\hline 5 or more & $\begin{array}{c}290211 \\
(20.1)\end{array}$ & $\begin{array}{c}1.74 \\
(1.72-1.76)\end{array}$ & $\begin{array}{c}1.20 \\
(1.20-1.21)\end{array}$ & $\begin{array}{c}1.27 \\
(1.25-1.28)\end{array}$ & $\begin{array}{c}1.61 \\
(1.59-1.63)\end{array}$ & $\begin{array}{c}1.30 \\
(1.26-1.33)\end{array}$ \\
\hline Age $\geq 85 \mathrm{yr}$ & 610548 & & & & & \\
\hline None & $\begin{array}{c}70565 \\
(11.6)\end{array}$ & $\begin{array}{c}6.48 \\
(6.18-6.79)\end{array}$ & $\begin{array}{c}4.48 \\
(4.37-4.59)\end{array}$ & $\begin{array}{c}4.71 \\
(4.33-5.12)\end{array}$ & $\begin{array}{c}10.48 \\
(9.24-11.89)\end{array}$ & $\begin{array}{c}22.00 \\
(17.15-28.24)\end{array}$ \\
\hline 1 & $\begin{array}{c}60779 \\
(10.0)\end{array}$ & $\begin{array}{c}2.20 \\
(2.13-2.26)\end{array}$ & $\begin{array}{c}1.50 \\
(1.48-1.52)\end{array}$ & $\begin{array}{c}1.73 \\
(1.65-1.80)\end{array}$ & $\begin{array}{c}3.12 \\
(2.93-3.32)\end{array}$ & $\begin{array}{c}3.48 \\
(3.13-3.88)\end{array}$ \\
\hline 2 & $\begin{array}{l}97128 \\
(15.9)\end{array}$ & $\begin{array}{c}2.14 \\
(2.10-2.19)\end{array}$ & $\begin{array}{c}1.35 \\
(1.34-1.37)\end{array}$ & $\begin{array}{c}1.48 \\
(1.44-1.52)\end{array}$ & $\begin{array}{c}2.53 \\
(2.44-2.63)\end{array}$ & $\begin{array}{c}2.29 \\
(2.14-2.45)\end{array}$ \\
\hline 3 & $\begin{array}{c}107891 \\
(17.7)\end{array}$ & $\begin{array}{c}2.03 \\
(1.99-2.07)\end{array}$ & $\begin{array}{c}1.30 \\
(1.29-1.31)\end{array}$ & $\begin{array}{c}1.27 \\
(1.25-1.30)\end{array}$ & $\begin{array}{c}2.01 \\
(1.95-2.07)\end{array}$ & $\begin{array}{c}1.63 \\
(1.56-1.72)\end{array}$ \\
\hline 4 & $\begin{array}{c}93241 \\
(15.3)\end{array}$ & $\begin{array}{c}1.85 \\
(1.81-1.88)\end{array}$ & $\begin{array}{c}1.26 \\
(1.25-1.27)\end{array}$ & $\begin{array}{c}1.18 \\
(1.16-1.20)\end{array}$ & $\begin{array}{c}1.60 \\
(1.56-1.65)\end{array}$ & $\begin{array}{c}1.26 \\
(1.21-1.31)\end{array}$ \\
\hline 5 or more & $\begin{array}{c}180944 \\
(29.6)\end{array}$ & $\begin{array}{c}1.54 \\
(1.52-1.55)\end{array}$ & $\begin{array}{c}1.23 \\
(1.23-1.24)\end{array}$ & $\begin{array}{c}1.09 \\
(1.07-1.10)\end{array}$ & $\begin{array}{c}1.32 \\
(1.30-1.34) \\
\end{array}$ & $\begin{array}{c}1.08 \\
(1.06-1.11)\end{array}$ \\
\hline \multicolumn{7}{|c|}{$\begin{array}{l}\text { Note: } \mathrm{Cl}=\text { confidence interval, } \mathrm{ED}=\text { emergency department, } \mathrm{HR}=\text { hazard ratio, } \mathrm{RR}=\text { rate ratio. Ratios are adjusted for sex, Aboriginal status and } \\
\text { rural/urban residence. These models include } 3 \text {-way and } 2 \text {-way interaction terms for dementia, age and number of morbidities. The table shows the } \\
\text { likelihood of a } 2 \text {-fold increase in the risk of the outcomes with repeat events (i.e., physician visits, ED visits, hospital admissions) that is associated } \\
\text { with dementia, along with the risk of mortality and discharge to long-term care. For example, in participants age } 65-74 \text { years with no comorbidities, } \\
\text { the presence of dementia is } 1.79 \text { times more likely to be associated with a } 2 \text {-fold increase in the number of physician visits, compared with } \\
\text { participants of similar age and with no comorbidities, but without dementia. }\end{array}$} \\
\hline
\end{tabular}


ple, the absolute likelihood of discharge to a long-term care facility (over a 5 -year period) was $0.6 \%, 3.3 \%$ and $12.0 \%$ for participants aged $65-74,75-84$ and at least 85 years, respectively; among participants 85 years and older, these proportions were $1.7 \%, 2.6 \%, 4.8 \%$ and $10.7 \%$ for those with 2,3 , 4 , or 5 or more morbidities but without dementia, and $28.0 \%, 35.6 \%, 37.6 \%$ and $46.9 \%$ for those with $2,3,4$, or 5 or more morbidities as well as dementia.

\section{Interpretation}

In this population-based study of more than 600000 communitydwelling people aged 65 years and older, we examined how increasing age and burden of chronic conditions modify the association between dementia and adverse health outcomes. As previously reported, the risk of poor outcomes increases in parallel with age and the number of morbidities. ${ }^{2,20} \mathrm{We}$ found that the presence of dementia acted as a risk multiplier across all age and morbidity strata, leading to worse health outcomes, especially for the risks of death or discharge to a long-term care facility. Although the clinical impact of dementia is already considerable, we also found a relatively slow but consistent increase in the prevalence of dementia over time: $0.2 \%$ per year, or approximately 13700 people per decade in Alberta. To put this statistic into context, the current capacity of Alberta's long-term care facilities is approximately 14000 people. While not all people with dementia will lose the capacity to live independently, these findings have clear implications for health systems and for the people responsible for planning and providing long-term care.

As a result of lower birth rates and longer life expectancy, the proportion of older people in the general population is steadily

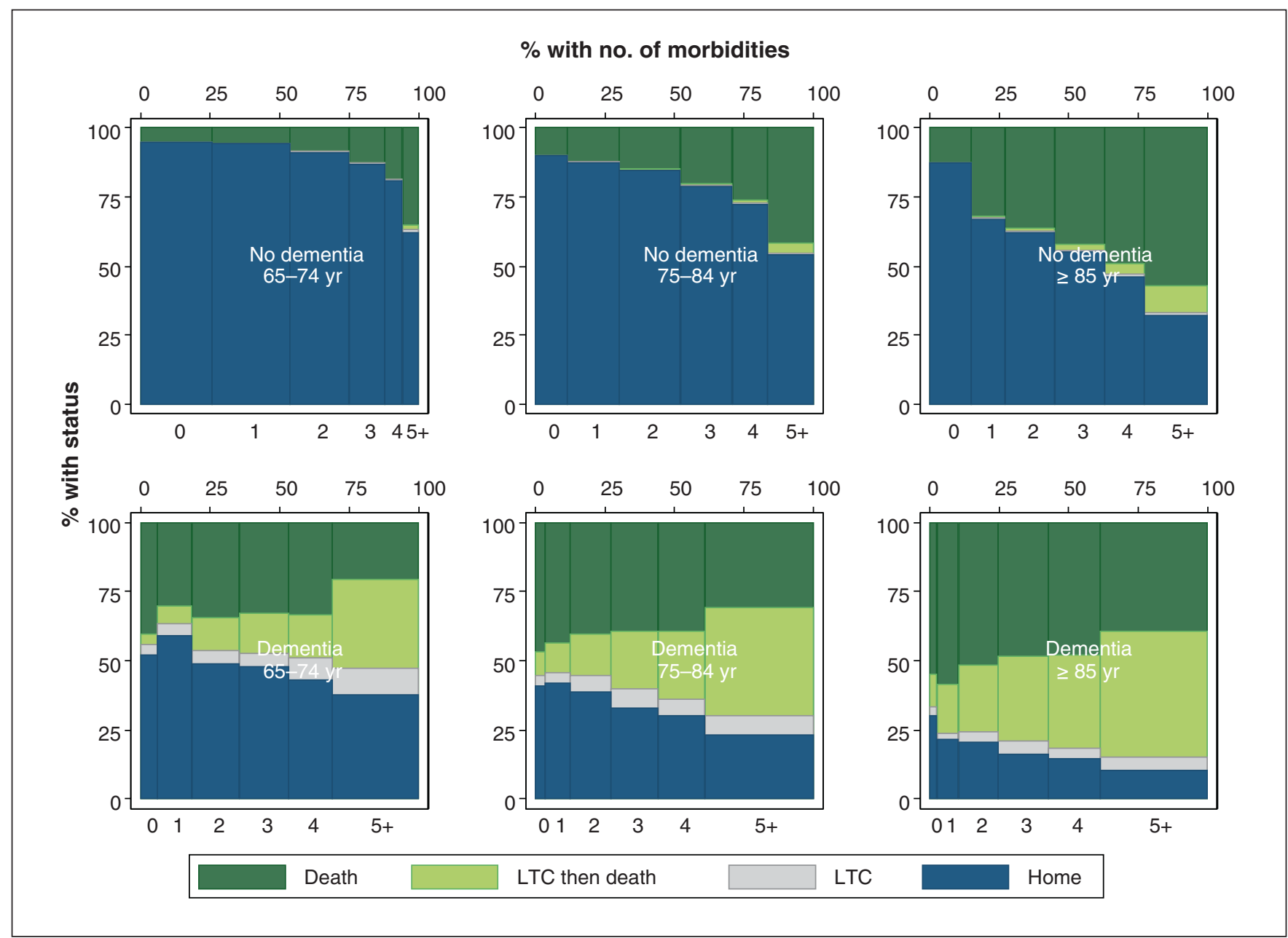

Figure 3: Relative proportion of deaths versus discharges to a long-term facility after 5 years by age, presence/absence of dementia, and number of morbidities. For this analysis, age and the presence/absence of dementia and other morbidities were assessed in fiscal year 2006. Clinical status (death; discharge to LTC facility) was assessed 5 years later in fiscal year 2011. The top row shows participants with no dementia. The bottom row shows participants with dementia. The left-most column shows participants age $65-74$ years, the middle column shows participants age 75-84 years and the right-most column shows participants age 85 years or older. Within each graph, the bars from left to right show the number of morbidities by group, starting at 0 morbidities and ending at 5 or more. The width of each bar indicates the percentage of participants in each group. The height of each bar indicates clinical status: the unadjusted percentage of participants who were alive without discharge to LTC facility (dark blue), alive but discharged to LTC placement after a hospital admission (grey), deceased but discharged to LTC placement previously (light green), or deceased and never discharged to LTC placement (dark green). Note: LTC = long-term care. 
increasing worldwide. ${ }^{7}$ Longer lifespans and the potential societal benefits associated with these demographic changes are to be celebrated, but population aging also poses numerous challenges for policy-makers. Although the age-related natures of both multimorbidity and dementia are well known, few studies have examined how the interplay between age, multimorbidity and dementia influences health outcomes or the capacity for independent living. Available studies demonstrate that increased morbidity burden is associated with higher prevalence and severity of dementia and cognitive impairment, ${ }^{8-11,21-24}$ but they are limited by their relatively small sample sizes and lack of longitudinal follow-up for clinical outcomes or resource use. Possible explanations for the high prevalence of comorbidities in people with dementia include common risk factors (e.g., unhealthy diet), a common causal pathway (e.g., atherosclerosis), adverse effects of medications used to treat medical morbidity, or other iatrogenic factors (e.g., subclinical stroke following angioplasty for coronary disease).

The landmark House of Lords report entitled Ready For Aging? focused on the implications of the aging population for the United Kingdom in 2020-2030, ${ }^{25}$ and it singled out dementia as an age-related condition that will require specific policy remedies aimed at prevention, management, harm reduction and social inclusion. Our findings strongly validate this conclusion and suggest that such policy remedies could produce considerable benefits. Areas of focus for such strategies could include health promotion (reducing the risk of dementia and other morbidities), self-care (perhaps through increased use of technology to improve function and reduce disability), tailored care for older patients with multimorbidity (accounting for interactions between conditions and the medications used to treat them, as well as the side effects of medicines that are more commonly used with increasing age), better integration between health and social care (to delay or prevent loss of independent living), and ensuring that the workforce has sufficient capacity and expertise to meet the needs of older people. ${ }^{26-28}$ Additional research should focus on how best to achieve these objectives.

\section{Limitations}

Our study has important strengths, including its use of a large population-based database from a setting with universal health care coverage, its use of validated algorithms for ascertaining the presence or absence of morbidity and its rigorous analytical methods. However, our study also has several potential limitations that should be considered when interpreting results. First, like all studies using administrative data, it is possible that there was residual confounding by unmeasured characteristics (e.g., smoking, body mass index, physical activity, and the extent of support from family members and other caregivers), and not all data elements have been validated. Second, since participants must use medical services to be diagnosed with chronic conditions, the use of administrative data to identify morbidities will underestimate the true population burden of dementia and other morbidities. Similarly, the excess risk associated with milder forms of dementia not requiring medical attention may be less pronounced than suggested here. In addition, we did not have algorithms for certain potentially important morbidities such as osteoporosis and frailty. However, given that utilization of medical services increases with age, our focus on people aged 65 years and older at baseline should reduce the extent of such underestimation. Third, when applied to ICD-10 claims, the validated algorithm that we used for dementia has a positive predictive value of $93 \%$ and sensitivity of $67 \%$, as compared with a clinical gold standard. ${ }^{18}$ Therefore, our findings will underestimate the true prevalence of dementia in Alberta. Fourth, our claims database allowed us to identify only people who were discharged from hospital to a long-term care facility. Since some older people enter long-term care facilities directly from home, our findings will underestimate the total percentage of people within each age stratum who eventually require longterm care. Fifth, we did not report on the incidence of dementia, because our design better captures prevalent cases; patients who develop dementia but die before they are captured as having dementia in claims data will be incorrectly omitted from estimates of dementia incidence but correctly omitted for estimates of dementia prevalence. Sixth, we studied people from a single Canadian province and our findings may not apply to other settings, although the demographic and health care challenges faced in this province are shared with all developed and many developing countries.

\section{Conclusion}

Like multimorbidity, the prevalence of dementia increases with increasing age, and age, burden of morbidity and dementia together are strongly correlated with adverse health outcomes and a proxy for loss of independent living. These findings and the secular trends in the population prevalence of dementia suggest the need for coordinated national strategies to mitigate the health challenges associated with the aging of the general population.

\section{References}

1. Fortin M, Lapointe L, Hudon C, et al. Multimorbidity is common to family practice. Is it commonly researched? Can Fam Physician 2005;51:244-5.

2. Barnett K, Mercer SW, Norbury M, et al. Epidemiology of multimorbidity and implications for health care, research, and medical education: a crosssectional study. Lancet 2012;380:37-43.

3. Fortin M, Hudon C, Haggerty J, et al. Prevalence estimates of multimorbidity: a comparative study of two sources. BMC Health Serv Res 2010;10:111.

4. Lehnert T, Heider D, Leicht H, et al. Review: health care utilization and costs of elderly persons with multiple chronic conditions. Med Care Res Rev 2011; 68:387-420.

5. Perruccio AV, Katz JN, Losina E. Health burden in chronic disease: multimorbidity is associated with self-rated health more than medical comorbidity alone. 7 Clin Epidemiol 2012;65:100-6.

6. Sinha SK. Living longer, living well: report submitted to the Minister of Health and Long-Term Care and the Minister Responsible for Seniors on recommendations to inform a Seniors Strategy for Ontario. Toronto: Ontario Ministry of Health and Long-Term Care; 2012. Available: www.health.gov. on.ca/en/common/ministry/publications/reports/seniors_strategy/ (accessed 2016 Apr. 14).

7. Good health adds life to years: global brief for World Health Day 2012. Geneva: World Health Organization; 2012. Available: www.who.int/iris/ handle/10665/70853 (accessed 2015 July 31).

8. Roberts RO, Cha RH, Mielke MM, et al. Risk and protective factors for cognitive impairment in persons aged 85 years and older. Neurology 2015;84:1854-61.

9. Vassilaki M, Aakre JA, Cha RH, et al. Multimorbidity and risk of mild cognitive impairment. 7 Am Geriatr Soc 2015;63:1783-90. 
10. Melis RJ, Marengoni A, Rizzuto D, et al. The influence of multimorbidity on clinical progression of dementia in a population-based cohort. PLoS One 2013;8:e84014.

11. Doraiswamy PM, Leon J, Cummings JL, et al. Prevalence and impact of medical comorbidity in Alzheimer's disease. 7 Gerontol A Biol Sci Med Sci 2002;57:M173-7.

12. Parekh AK, Goodman RA, Gordon C, et al.; HHS Interagency Workgroup on Multiple Chronic Conditions. Managing multiple chronic conditions: a strategic framework for improving health outcomes and quality of life. Public Health Rep 2011;126:460-71.

13. Thompson S, James M, Wiebe N, et al.; Alberta Kidney Disease Network. Cause of death in patients with reduced kidney function. 7 Am Soc Nephrol 2015;26:2504-11.

14. Tonelli M, Muntner P, Lloyd A, et al.; Alberta Kidney Disease Network. Risk of coronary events in people with chronic kidney disease compared with those with diabetes: a population-level cohort study. Lancet 2012;380:807-14.

15. Alexander RT, Hemmelgarn BR, Wiebe N, et al.; Alberta Kidney Disease Network. Kidney stones and kidney function loss: a cohort study. BM7 2012;345:e5287.

16. Hemmelgarn BR, Clement F, Manns BJ, et al. Overview of the Alberta Kidney Disease Network. BMC Nephrol 2009;10:30.

17. Tonelli M, Wiebe N, Martin F, et al.; Alberta Kidney Disease Network. Methods for identifying 30 chronic conditions: application to administrative data. BMC Med Inform Decis Mak 2015;15:31.

18. Quan H, Li B, Saunders LD, et al.; IMECCHI Investigators. Assessing validity of ICD-9-CM and ICD-10 administrative data in recording clinical conditions in a unique dually coded database. Health Serv Res 2008;43:1424-41.

19. Stevens PE, Levin A; Kidney Disease: Improving Global Outcomes Chronic Kidney Disease Guideline Development Work Group Members. Evaluation and management of chronic kidney disease: synopsis of the kidney disease: improving global outcomes 2012 clinical practice guideline. Ann Intern Med 2013;158:825-30.

20. Tonelli M, Wiebe N, Guthrie B, et al. Comorbidity as a driver of adverse outcomes in people with chronic kidney disease. Kidney Int 2015;88:859-66.

21. Solomon A, Dobranici L, Kåreholt I, et al. Comorbidity and the rate of cognitive decline in patients with Alzheimer dementia. Int 7 Geriatr Psychiatry 2011;26:1244-51.

22. Griffith LE, Gruneir A, Fisher K, et al. Patterns of health service use in community living older adults with dementia and comorbid conditions: a population-based retrospective cohort study in Ontario, Canada. BMC Geriatr 2016;16:177.

23. Melis R, Marengoni A, Angleman S, et al. Incidence and predictors of multimorbidity in the elderly: a population-based longitudinal study. PLoS One 2014;9:e103120.

24. Bunn F, Burn AM, Goodman C, et al. Comorbidity and dementia: a scoping review of the literature. BMC Med 2014;12:192.

25. Select Committee on Public Service and Demographic Change. Ready for ageing? [report]. London (UK): House of Lords; 2013.

26. Beard JR, Bloom DE. Towards a comprehensive public health response to population ageing. Lancet 2015;385:658-61.
27. Banerjee S. Multimorbidity - older adults need health care that can count past one. Lancet 2015;385:587-9.

28. Rechel B, Grundy E, Robine JM, et al. Ageing in the European Union. Lancet 2013;381:1312-22.

Affiliations: Department of Medicine (Tonelli, James, Tam-Tham, Manns, Hemmelgarn), University of Calgary, Calgary, Alta.; Department of Medicine (Wiebe, Klarenbach), University of Alberta, Edmonton, Alta.; Department of Medicine (Straus), University of Toronto, Toronto, Ont.; Department of Family Medicine (Fortin), Université de Sherbrooke, Sherbrooke, Que.; Population Health Sciences Division (Guthrie), Medical Research Institute, University of Dundee, Dundee, UK; Alberta Health Services (Lewanczuk, Sargious), Edmonton, Alta.; Department of Community Health Sciences (Quan, Ronksley), University of Calgary, Calgary, Alta.

Contributors: Marcello Tonelli and Sharon Straus conceived the study. Marcello Tonelli and Natasha Wiebe designed the study and drafted the manuscript. Natasha Wiebe performed the statistical analyses. All authors made substantial contributions to the development of the manuscript, all were involved in revising it for important intellectual content and all approved the final version. Marcello Tonelli had full access to all of the data in the study and takes responsibility for the integrity of the data and the accuracy of the data analysis.

Funding: This work was supported by the Canadian Institutes for Health Research (MOP 133582), by a team grant to the Interdisciplinary Chronic Disease Collaboration from Alberta Innovates - Health Solutions and by a Leaders Opportunity Fund grant from the Canada Foundation for Innovation. Marcello Tonelli, Hude Quan and Scott Klarenbach are supported by career salary awards from Alberta Innovates - Health Solutions. This study is based in part on data provided by Alberta Health and Alberta Health Services. The interpretation and conclusions are those of the researchers and do not represent the views of the government of Alberta. The funders had no role in the design or analysis of this study, nor the drafting or approval of this manuscript. Neither the government of Alberta nor Alberta Health expresses any opinion in relation to this study. The corresponding author has access to all the data in the study and takes responsibility for the integrity of the data and the accuracy of the data analysis.

Acknowledgements: The authors of this report are grateful to Sophanny Tiv for figure construction and Ghenette Houston for administrative support.

Supplemental information: For reviewer comments and the original submission of this manuscript, please see www.cmajopen.ca/content/5/3/ E623/suppl/DC1. 